\title{
Effectiveness of monetary policy under different levels of capital flows for an emerging economy: Turkey
}

\section{Volkan Ülke \& Hakan Berument}

To cite this article: Volkan Ülke \& Hakan Berument (2015) Effectiveness of monetary policy under different levels of capital flows for an emerging economy: Turkey, Applied Economics Letters, 22:6, 441-445, DOI: 10.1080/13504851.2014.948668

To link to this article: https://doi.org/10.1080/13504851.2014.948668

Published online: 15 Aug 2014.

Submit your article to this journal 주

Џll Article views: 298

View Crossmark data $\complement$ 


\title{
Effectiveness of monetary policy under different levels of capital flows for an emerging economy: Turkey
}

\author{
Volkan Ülke ${ }^{\mathrm{a}}$ and Hakan Berument ${ }^{\mathrm{b}, *}$ \\ ${ }^{\mathrm{a}}$ Faculty of Economics, International Burch University, Sarajevo, Bosnia \\ and Herzegovina \\ ${ }^{\mathrm{b}}$ Department of Economics, Bilkent University, 06800 Ankara, Turkey
}

This article assesses the effect of tight monetary policy on economic performance under different levels of capital flows. Empirical evidence from Turkey between 1990 and 2013 suggests that tight monetary policy measured with a positive innovation on interest rate appreciates the Turkish Lira and decreases output and prices. However, the effectiveness of monetary policy decreases for interest rate and increases for exchange rate and prices if capital flows are high. Specifically, interest rate, local currency value of foreign currency and prices will be lower for higher levels of capital flows. However, the relative effectiveness of monetary policy on output is virtually unchanged.

Keywords: monetary policy; capital flows; interacted VAR

JEL Classification: E52; F21; F32; F41

\section{Introduction}

With the financial market globalization, especially in the post-2008 era, the role of capital flows has become more important. Despite the welldocumented benefits of capital flows, high levels offer a set of challenges to policymakers, such as limiting their influence on economic outcomes. For example, central banks have less power to affect national liquidity, such as domestic money supply, with higher levels of capital flows, and thus have less power to influence a country's economic performance (see, Giannoni and Boivin, 2008; Belke et al., 2009; Devereux and Yetman, 2013). The purpose of this article is to provide empirical evidence on how the effect of monetary policy on economic performance changes with different levels of capital flows for a small open economy, Turkey, and directly assesses that evidence by using the innovative interactive vector autoregression (IVAR) model.

Short-term interest rates used by central banks to implement their monetary policy also affect their countries' capital flows. Capital flows also provide extra liquidity to a country in addition to the liquidity provided by the central bank. Thus, the effect of the same level of interest rate changes will have a different effect on economic performance if capital flows are higher versus lower. The existing literature

\footnotetext{
*Corresponding author. E-mail: berument@bilkent.edu.tr
} 
on the effect of monetary policy on economic performance for different levels of capital flows uses methods such as the factor-augmented VAR (for example, Giannoni and Boivin, 2008; Belke et al., 2009; Belke and Rees, 2014, forthcoming) and general equilibrium models (for example, Devereux and Yetman, 2013). This article, however, employs the IVAR method developed by Towbin and Weber (2010), a novel and more direct form of capturing the differentiated effect, and uses data from Turkey.

The article continues as follows: Section Two introduces the econometric methodology. Section Three discusses the data set. Section Four discusses the empirical evidence from Turkey. Section Five concludes.

\section{Methodology}

The IVAR model that we use is a modified version of Saborowski and Weber (2013) interactive panel VAR specification: $Y_{t}$ is a $q$-variable vector of the explanatory variables and $X_{t}$ stands for the interacted variables. Our IVAR(p) model can be represented as

$$
\begin{aligned}
A_{0} Y_{t}= & C+\sum_{k=1}^{p} A_{k} Y_{t-k}+D X_{t} \\
& +\sum_{k=1}^{p} B_{k} X_{t} Y_{t-k}+u_{t}, \quad \text { where } t=1,2, \ldots, T
\end{aligned}
$$

The dynamic relationship between endogenous variables and interacted variables can be represented as $X_{t} Y_{t-k} \cdot X_{t} Y_{t-k}$ is the interaction term. $C$ is the $q$-vector of the intercept term and dummy variables. $A_{k}, B_{k}$ and $D$ comprise the $q \times q$ matrix of coefficients. $u_{t}$ stands for the $q$-vector of residuals. $p$ is the lag order. $A_{0}$ is recursive IVAR coefficient that identifies the structure of the model by constructing the error term in each regression to be uncorrelated with the error in the preceding equations. To be able to make inferences, the impulse response functions are gathered at different levels of $X_{t}$. Later, we compare these impulse responses for a shock given to elements of the $u_{t}$ vector to understand how the different levels of $X_{t}$ will affect the behaviours of $Y_{t}$ in that scenario.

\section{Data}

To construct an IVAR model, we use monthly data from January 1990 to September 2013. Our $Y_{t}$ vector includes the interbank overnight interest rate as interest, the domestic currency value of one US dollar as exchange rate, industrial production as output and the consumer price index as prices. We use portfolio investment and current account deficit as measures of capital flows for the interactive term $X_{t}$ separately. These two variables are deflated with the lag values of the interpolated monthly GDP to standardize them. We use this lag value to eliminate the effect of capital flows on GDP. All data is gathered from the CBRT's electronic data delivery system (EDDS) and the interest rate data is supplemented with overnight interest data from the EDDS and Borsa İstanbul (BIST) databases after 2000.

\section{Empirical Evidence}

It is expected that a tight monetary policy associated with higher interest rates will lead to a nominal appreciation of the domestic currency for a given expected inflation rate. This policy also decreases prices and does not increase the output level (see, for example, Kim and Roubini, 2000; Berument, 2007).

Under higher levels of capital flows, appreciation will be higher and price decreases will be greater due to the higher degree of exchange-rate pass-through. Determining the effect of higher interest rates on output is a more complicated issue. On one hand, when local currency appreciates, it decreases the competitiveness of domestically produced tradable goods, and thus net export, and ultimately decreases output (see, for example, Cordero and Montecino, 2010). However, due to factors such as low import input prices, investment goods, the domestic value of foreign currency and denominated liabilities, appreciation boosts the economy (see Kamin and Rogers, 2000). Berument and Pasaogullari (2003)provide empirical evidence for the latter from Turkey. Thus, under higher levels of capital, the effect of monetary policy will be greater on appreciation and prices while the effect of appreciation on output will be ambiguous.

To identify a monetary policy stance, by following Christiano et al. (1999), we specify a VAR model that employs the Cholesky decomposition. Here, the order of the variables for the vector $Y_{t}$ is important, and we order them as interest rate, exchange rate, industrial production and prices. We also use two different series as the interaction term: hot money 
(portfolio investment deflated with the lag value of the interpolated GDP ${ }^{1}$ ) and current account (current account deflated with the lag value of the interpolated GDP). The exchange rate, industrial production and price variables enter the system in their natural logarithms, and interest rate on its level. To account for seasonality we include 11 monthly dummies, and to account for financial crises we include intercept dummies for 1994:03, 1994:05, 2000:12 and 2001:02 - Turkish financial crises periods.

Figure 1 reports the impulse responses for six periods when a one-standard-deviation shock is given to interest rate for interest rate, exchange rate, industrial production and prices. Here, we use portfolio investment as the interaction term. In the first three columns, the middle line shows the median of estimates and the other two lines show the bootstrapped confidence intervals at the $95 \%$ level, which are computed using 2000 replications. The fourth column shows the estimates of these three different conditions together for each variable. In the first column we set capital flows to zero. In the second column capital flows were equal to the tenth percentile, and in the third column they were equal to the ninetieth percentile.

The first column suggests that a contractionary monetary policy shock under no capital flows decreases industrial production and prices and appreciates domestic currency. The second column reports impulse responses when there are capital flows at the tenth percentile. A contractionary monetary policy decreases exchange rate (appreciation), industrial production and prices similarly. However, the effects on interest rate and prices increase up to three periods (in a statistically significant fashion) when capital flows are higher. The effect of interest
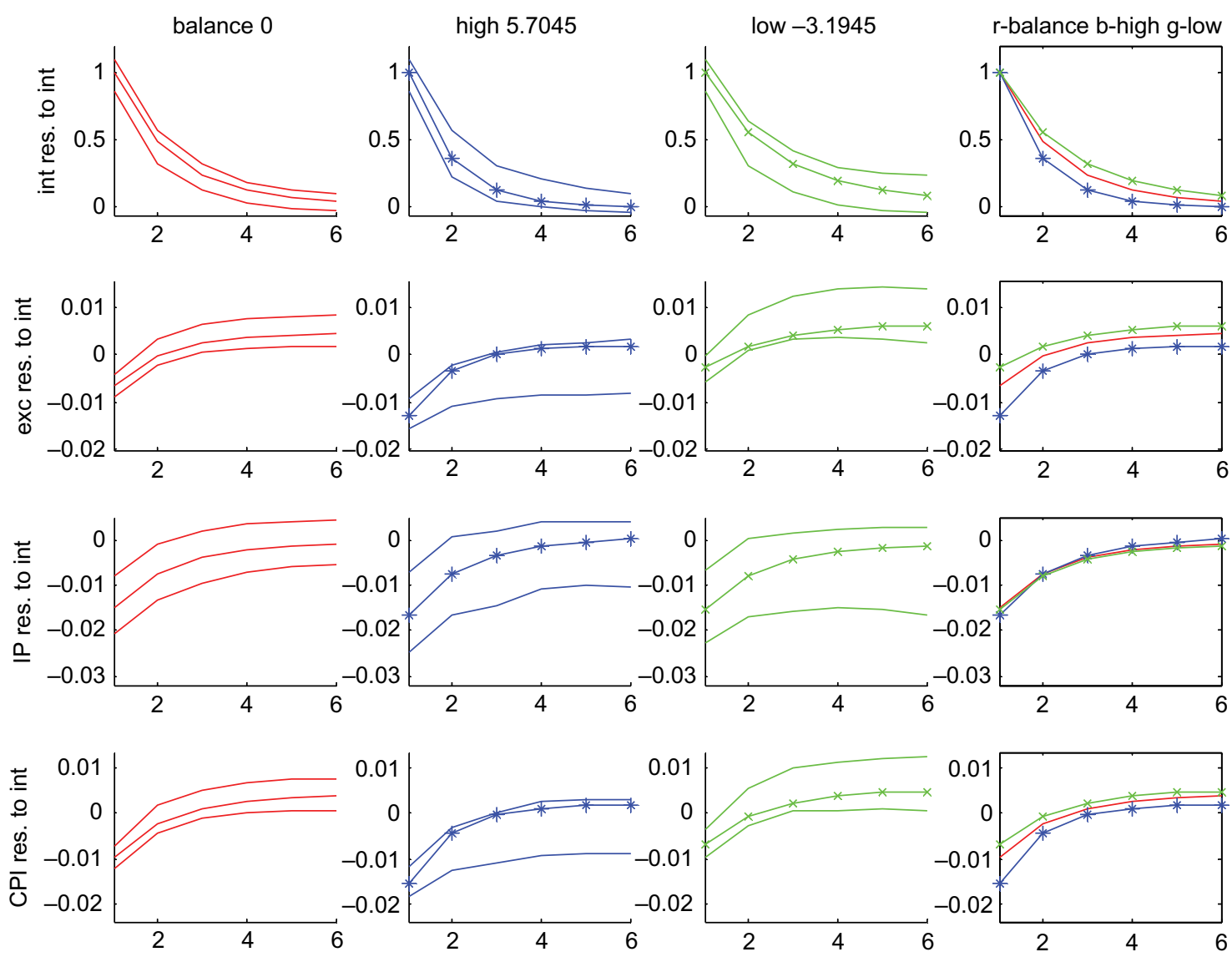

Fig. 1. Impulse responses for $1 \%$ interest rate shock under capital flows (portfolio investment to GDP ratio) with $95 \%$ confidence band

\footnotetext{
${ }^{1}$ We deflate the portfolio investment with the lagged (rather than the current) value of the interpolated GDP to avoid simultaneity bias.
} 
rate increases on output is almost identical when there are capital inflows. The third column repeats the exercise when capital outflows are at the ninetieth percentile. Similarly, a contractionary monetary policy decreases exchange rate, industrial production and prices. However, the effects of interest rate and prices decrease when capital flows are lower or when there are capital outflows. The effects of interest rate shock are qualitatively similar to the first two columns. When we compare these three impulse responses in column four, we observe that (a) a shock to interest rate is less persistent, (b) the effect on exchange is higher, (c) the decrease in prices is more when capital inflow is higher and (d) the effect of interest rate on output is similar across the three impulse response functions. Thus, the effect of interest rate on all variables but output is higher under capital inflow.

Identifying monetary policy with the VAR methodology is often criticized due to the well-established puzzles that impulse response functions produce, such as unexpected changes in price, exchange rate and liquidity when a one-standard-deviation shock is introduced to interest rates. In our analysis, all the variables respond to a contractionary monetary policy shock in such a way that they do not produce the above puzzles.

Trade flows may also affect monetary policy. Thus, we repeat the exercise with current account deficit as the interactive term (see Fig. 2). The initial impacts of positive innovation on interest rate for interest rate, exchange rate and prices are similar to those reported in Fig. 1. Moreover, as in Fig. 1, the decrease in all the variables except industrial production is greater when there are capital inflows than when there are capital outflows or a balanced current account deficit. When impulse responses are examined carefully, it seems that a tight monetary policy depreciates currency and increases prices in the long run when there are capital outflows. However, this does not prevail in capital-inflow or no-capitalinflow cases.
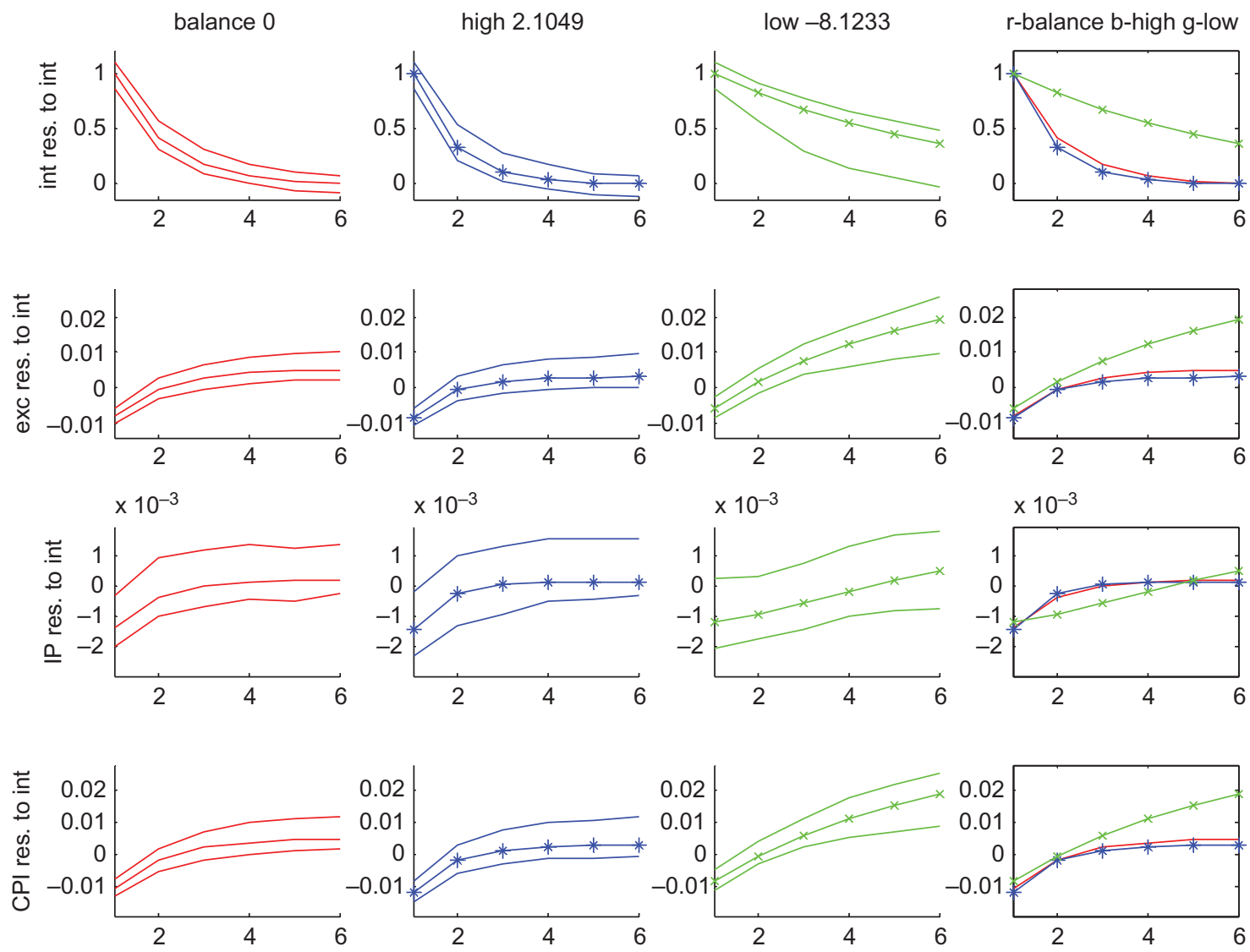

Fig. 2. Impulse responses for $1 \%$ interest rate shock under current account (current account deficit to GDP ratio) with $95 \%$ confidence band 


\section{Conclusion}

Empirical evidence from Turkey suggests that a positive innovation in interest rate appreciates the Turkish Lira and decreases output and prices. However, the effectiveness of monetary policy decreases for interest rates but increases for local currency and prices when capital inflows are higher. Specifically, interest rate, local currency value of foreign currency and prices will be lower under higher levels of capital inflows, but the effectiveness of monetary policy on output is virtually unchanged. These findings have implications for monetary policy frameworks and for monitoring excessive external imbalances. In particular, our analysis indicates that there is a strong relevance between capital flows and the effectiveness of interest rate as a monetary policy tool.

\section{Acknowledgement}

We would like to thank Sebastian Weber for sharing the PIVAR codes and Rana Nelson for her valuable suggestions.

\section{References}

Belke, A., and Rees, A. (2009) The importance of global shocks for national policy makers - rising challenges for central banks, Ruhr Economic Paper No. 135, Rheinisch-Westfälisches Institut für Wirtschaftsforschung, Ruhr-Universität Bochum, Universität Dortmund, Universität Duisburg-Essen. doi:10.3790/978-3-428-53254-4

Belke, A. and Rees, A. (2014, forthcoming) Globalisation and monetary policy-A FAVAR analysis for the G7 and the eurozone, The North American Journal of Economics and Finance. doi:10.1016/j. najef.2014.06.003
Berument, H. (2007) Measuring monetary policy for a small open economy: Turkey, Journal of Macroeconomics, 29, 411-30. doi:10.1016/j. jmacro.2006.02.001

Berument, H. and Pasaogullari, M. (2003) Effects of the real exchange rate on output and inflation: evidence from Turkey, The Developing Economies, 41, 40135. doi:10.1111/j.1746-1049.2003.tb01009.x

Christiano, L. J., Eichenbaum, M. and Evans, C. L. (1999) Chapter 2 monetary policy shocks: what have we learned and to what end?, Handbook of Macroeconomics, Vol. 1A, North-Holland, pp. 65148. doi:10.1016/S1574-0048(99)01005-8

Cordero, J. A. and Montecino, J. A. (2010) Capital controls and monetary policy in developing countries (report), Center for Economic and Policy Research (CEPR), Washington, DC.

Devereux, M. B. and Yetman, J. (2013) Capital controls, global liquidity traps and the international policy trilemma, NBER Working Paper No. 19091, National Bureau of Economic Research, Cambridge, MA.

Giannoni, M. and Boivin, J. (2008) Global forces and monetary policy effectiveness, 2008 Meeting Paper No. 1067, Society for Economic Dynamics, Cambridge, MA.

Kamin, S. B. and Rogers, J. H. (2000) Output and the real exchange rate in developing countries: an application to Mexico, Journal of Development Economics, 61, 85-109. doi:10.1016/S0304-3878 (99)00062-0

Kim, S. and Roubini, N. (2000) Exchange rate anomalies in the industrial countries: a solution with a structural VAR approach, Journal of Monetary Economics, 45, 561-86. doi:10.1016/S0304-3932(00)00010-6

Saborowski, C. and Weber, S. (2013) Assessing the determinants of interest rate transmission through conditional impulse response functions, IMF Working Paper No. 13/23, International Monetary Fund, IMF European Department, Washington, DC.

Towbin, P. and Weber, S. (2010) Limits of floats: the role of foreign currency debt and import structure, IHEID Working Paper No. 01-2010, Economics Section, The Graduate Institute of International Studies, Geneva. 